\begin{tabular}{|l|l|}
\hline Recebido: & $09 / 08 / 2020$ \\
\hline Publicado: & $12 / 09 / 2020$ \\
\hline
\end{tabular}

\title{
A PSICOLOGIA HOSPITALAR E A HUMANIZAÇÃO NO HOSPITAL: UM RELATO DE EXPERIÊNCIA
}

\author{
Karolina Reis dos Santos Lukachaki ${ }^{i} \oplus 0000-0003-0649-5107$ \\ Universidade Estadual de Maringá - UEM \\ Barbara Carolina Lima de Oliveira ${ }^{\text {ii }} \odot 0000-0003-3156-4418$ \\ Universidade Estadual de Maringá - UEM \\ Marília Daefiol Herrero Gomes ${ }^{\text {iii }} \oplus 0000-0002-7290-0636$ \\ Universidade Estadual de Maringá - UEM
}

RESUMO: O tema abordado por este trabalho é a Política de Humanização Nacional (PNH) do Sistema Único de Saúde (SUS). O objetivo deste artigo é, principalmente, discutir possibilidades de articulação entre a PNH e o serviço de psicologia dentro do hospital, destacando a importância do trabalho multiprofissional realizado pela equipe de saúde. Para tanto, buscamos relatar nossa experiência, enquanto duas estagiárias de Psicologia, no Hospital Universitário de Maringá (HUM). A partir do relato e das pesquisas que embasaram nossa experiência, ficou claro que toda a prática do psicólogo hospitalar é orientada pela humanização do cuidado. Também foi possível tornar as diretrizes da $\mathrm{PNH}$ mais palpáveis e ressaltar a potência e a relevância do escopo teórico e prático da Psicologia na implementação e manutenção dos processos de humanização, em especial, dentro de serviços de saúde de alta complexidade. Além disso, constatamos a escassez de trabalhos na área da Psicologia que explorassem a efetivação da PNH em hospitais. Por fim, destacamos a atual inviabilização de várias atividades de humanização no HUM diante da pandemia de COVID-19.

PALAVRAS-CHAVE: Psicologia hospitalar. Humanização. Relato de experiência.

\section{HOSPITAL PSYCHOLOGY AND HUMANIZATION IN THE HOSPITAL: AN EXPERIENCE REPORT}

\begin{abstract}
The theme addressed by this paper is the Política de Humanização Nacional - PNH ("National Humanization Policy") of the Sistema Único de Saúde (SUS). The purpose of this article is, mainly, to discuss connection possibilities between the PNH and the psychology team within the hospital, highlighting the importance of the multiprofessional work carried out by the healthcare team. Therefore, we seek to tell our experience, as two interns of Psychology, at the Hospital Universitário de Maringá (HUM). From the report and research that supported our experience, it was clear that the entire practice of the hospital psychologist is guided by care humanization. Also, it was possible to make PNH's guidelines more palpable and to emphasize the power and relevance of Psychology's theoretical and practical scope in the accomplishment and maintenance of
\end{abstract}

humanization processes, especially within highly complex health care services. In addition, we verified the scarcity of papers in the Psychology field that explored the implementation of PNH in hospitals. Finally, we highlighted the current impossibility of carrying out various humanization activities at HUM in the face of the COVID-19 pandemic.

KEYWORDS: Hospital psychology. Humanization. Experience report. 


\section{Introdução}

A hospitalização, como destaca Angerami-Camon (2003), é algo singular enquanto vivência. Fora os casos de doenças crônicas e/ou degenerativas em que há uma história prévia de contato com o ambiente hospitalar, e eventualidades como partos, tal acontecimento não é algo comumente listado nos planejamentos de vida. Quando acontece, diversos baques vêm a reboque. Desde não ser mais "Carlos" ou "Maria", para ser o "4C" ou "a amputação do 2B", até a obrigatoriedade repentina de mudança de hábitos longínquos.

A despersonalização, o estigma de doente, a limitação das escolhas e companhias, a mudança de espaço vital e constantes intervenções que se tornam invasivas permeiam o processo de hospitalização, tornando-o aversivo e entremeado de dor e desalento (ANGERAMI-CAMON, 2003). O autor, referência na área, pontua que se o psicólogo no contexto do hospital trabalhar visando estancar tais processos, ele contribuirá para a humanização do hospital.

Posto que é necessária a humanização dos serviços de saúde diante dos processos de despersonalização dos usuários, e outros, fica clara a importância da Política Nacional de Humanização (PNH) de 2003. Diante disso, o objetivo desse artigo é colocar a PNH em pauta, expondo possibilidades de articulação entre o trabalho da Psicologia Hospitalar e as diretrizes propostas pela PNH ao relatar como essa articulação tem sido feita dentro do Hospital Universitário de Maringá (HUM) sob o olhar de duas estagiárias de psicologia do projeto "Psicologia Hospitalar e Equipe Multiprofissional - Interdisciplinaridade na promoção de saúde". Para tanto, é necessário contemplar ligeiramente alguns aspectos históricos a respeito da saúde no Brasil até o surgimento da PNH, bem como contemplar brevemente a história e concepção da Psicologia Hospitalar no Brasil.

\subsection{Política Nacional de Humanização $(\mathrm{PNH})$}

Desde a chegada dos portugueses ao Brasil, a situação da saúde passou por diversos momentos de precariedade, em que grande parte da população permanecia desassistida. Apenas no início do século XX que se pode falar propriamente em políticas de saúde. Em 1953, houve a criação do Ministério da Saúde, órgão que até 1988 desenvolvia, quase exclusivamente, ações de controle de endemias e campanhas de vacinação. Na verdade, a atuação do setor público no âmbito da assistência médico-hospitalar acontecia apenas por intermédio do Instituto Nacional 
de Assistência Médica da Previdência Social (Inamps), que fazia parte do Ministério da Previdência e Assistência Social. O acesso à assistência à saúde era exclusividade dos trabalhadores da economia formal segurados do Instituto Nacional de Previdência Social (INPS) e seus dependentes, ou seja, não tinha caráter universal (BRASIL, 2011a).

Em 1986, na $8^{\text {a }}$ Conferência Nacional de Saúde, o Sistema Único de Saúde (SUS) foi criado, constituindo, finalmente, uma proposta de abrangência universal da população brasileira. Em 1988, a Constituição Federal, conhecida como Constituição Cidadã, aprovou a criação do SUS e, então, a saúde passou a ser considerada como um direito fundamental do cidadão que deve ser assegurado pelo Estado. A partir disso, há uma redefinição das prioridades do Estado na área da Saúde Pública e a saúde passa a ser concebida de forma mais ampla, não mais meramente como ausência de doenças. Nota-se, portanto, a transição para um modelo mais humano de assistência à saúde (BRASIL, 2011a; PEREIRA, 2019).

A partir da aprovação desse sistema, o desafio seguinte foi a implantação e consolidação das medidas previstas pelo arcabouço legal do SUS. De acordo com Pereira (2019), na 11 a Conferência Nacional da Saúde, em 2000, ficou claro que uma dessas dificuldades a serem enfrentadas dentro do sistema era o desinteresse pelos profissionais do SUS e o atendimento de má qualidade aos pacientes. A solução que foi apontada para tal desafio é justamente o aspecto que nos propusemos a explorar e analisar neste trabalho: as políticas de humanização do SUS.

Assim, em 2001 foi publicado o Programa Nacional de Humanização da Assistência Hospitalar (PNHAH). Entretanto a visão a respeito da humanização defendida pelo programa foi duramente criticada por relacioná-la a práticas de saúde fragmentadas ligadas ao assistencialismo e ao voluntarismo, aspectos que, de acordo com a crítica apresentada por Pereira (2019), não coincidem com nenhuma existência concreta (PASCHE; PASSOS, 2008).

Assim, buscando corrigir os "defeitos" apontados pela crítica no PNHAH, em 2003, o Ministério da Saúde lançou a Política Nacional de Saúde (PNH), vigente até hoje e cujo principal propósito é incentivar a melhoria da qualidade da atenção e da gestão da saúde no país, contribuindo com as suas diretrizes (PASCHE; PASSOS, 2008). De acordo com o Ministério da Saúde (BRASIL, 2011b), as diretrizes da PNH são: cogestão, acolhimento, clínica ampliada, ambiência, direito a acompanhante, visita aberta e valorização do trabalho e trabalhadores da saúde.

De forma breve, vamos expor as principais características dessas diretrizes para que, adiante, seja possível pensá-las dentro do hospital e discutir o papel da Psicologia Hospitalar na efetivação da política em questão. A primeira diretriz citada, a cogestão, tem relação com mudanças organizacionais, com uma nova forma de fazer gestão, espera-se que espaços 
coletivos sejam criados para gerar "[...] pactuações e condução de ações para mudanças das práticas de atenção e gestão" (BRASIL, 2011b, p. 21).

O acolhimento e a clínica ampliada são diretrizes muito semelhantes no sentido de que não são "coisas" que podem ser implantadas, mas ambas constituem novas possibilidades de se fazer clínica, buscando produzir dignidade e cidadania. O acolhimento diz respeito a "um compromisso coletivo em cultivar os vínculos de maneira responsável, reconhecendo e incluindo diferenças, estimulando a coprodução de autonomia e a valorização da vida em todos os encontros produzidos nos serviços de saúde. " (BRASIL, 2001b, p. 56). A clínica ampliada tem relação direta com uma concepção de saúde que excede os limites da concepção clássica que entende saúde como ausência de doenças, além disso, implica em considerar a existência de uma multiplicidade de vias de compreensão e de ação no processo conflito-adoecimentosofrimento. Essa diretriz provoca compartilhamento e qualificação da relação entre sujeitos, além disso, inclui os profissionais de saúde e o próprio paciente no processo de construção de diagnóstico, opções terapêuticas e etc. (BRASIL, 2011b).

A ambiência concerne "ao tratamento dado ao espaço físico entendido como espaço social, profissional, e de relações interpessoais que deve proporcionar atenção acolhedora, resolutiva e humana" (BRASIL, 2011b, p. 90). O direito a acompanhante e à visita aberta partem da reorganização do serviço de saúde para que seja possível atender o direito de o paciente ter sua rede de apoio familiar e social presente. Por fim, tem-se a valorização do trabalho e trabalhadores da saúde, que deve acontecer por meio da constituição de espaços e oportunidades "sistemáticas para análises coletivas do trabalho, com participação ativa dos trabalhadores, buscando a corresponsabilização com as avaliações e também com as propostas que sejam deliberadas como viáveis. " (BRASIL, 2011b, p. 24).

Os elementos que definem as diretrizes da PNH são abstratos e, apenas a partir deles, torna-se difícil pensar em ações concretas que estejam de acordo com a proposta de humanização dos serviços de saúde. Assim, pretendemos investi-los de materialidade com a exposição posterior, apresentando possibilidades de articulação entre a Psicologia Hospitalar ao expor nossa experiência enquanto estagiárias de psicologia no HUM. Para que isso seja possível, é necessário fazer um resgate histórico a respeito da Psicologia Hospitalar no Brasil, salientando suas principais funções e formas de atuar.

\subsection{Psicologia hospitalar}


A Psicologia Hospitalar no Brasil tem como marco histórico a atuação de Mathilde Neder na antiga Clínica Ortopédica e Traumatológica, hoje intitulada Instituto de Ortopedia e Traumatologia do Hospital das Clínicas da USP. Por volta de 1952, Mathilde começou o trabalho de acompanhamento psicológico de crianças que realizavam cirurgias de coluna e seus familiares. A partir de então, a psicóloga teve atuações significativas para a área, tornando-se pioneira no desenvolvimento da psicoterapia breve no Brasil (NEDER, 2005).

A terminologia "Psicologia Hospitalar", segundo Rudnicki e Schmidt (2015), é uma particularidade brasileira. Para além do território nacional, fala-se de Psicologia da Saúde. Pautada no conceito da OMS (1948) de "saúde" para além da ausência de doença, mas de completo bem-estar físico, social e mental, a Psicologia da Saúde é uma área da Psicologia que abarca os três níveis de atenção em saúde, que insere o profissional psi no trabalho em equipe multidisciplinar e que visa à compreensão dos fatores envolvidos na saúde e na doença, tanto de enfermos quanto de familiares e profissionais da saúde. Nessa perspectiva, a Psicologia Hospitalar seria um desdobramento da Psicologia da Saúde, configurando-se como um campo de atuação (RUDNICKI; SCHMIDT, 2015).

Em relação a atuação, a Resolução do CFP n013/2007, institui como psicólogo especialista em Psicologia Hospitalar aquele profissional que trabalha em instituições de ensino superior propiciando especializações e aprimoramentos na área, bem como, aquele que trabalha em instituições de saúde de nível secundário e terciário, objetivando "a avaliação e acompanhamento de intercorrências psíquicas dos pacientes que estão ou serão submetidos a procedimentos médicos, visando basicamente a promoção e/ou a recuperação da saúde física e mental" (CFP, 2007, p. 21) assim como, a atuação na mediação da relação entre paciente, familiares e equipe médica.

Isto posto, percebe-se que a Psicologia Hospitalar no Brasil foi se configurando ao longo dos anos com o desenvolvimento de saberes e fazeres específicos da atuação nesse contexto, na medida em que os profissionais foram se inserindo nas instituições e atravessando o cuidado e a atenção em saúde para além do nível básico. Adiante, procuraremos analisar como tal atuação se entrelaça com a PNH e como se efetua na prática, a partir do nosso relato de experiência.

\section{Estágio de Psicologia Hospitalar e Equipe Multiprofissional no HUM}

O Projeto "Psicologia Hospitalar e Equipe Multiprofissional - Interdisciplinaridade na promoção de saúde", vinculado à Diretoria de Extensão da Universidade Estadual de Maringá 
(UEM) desde 2004, outorga estágio não obrigatório em Psicologia Hospitalar no Hospital Universitário da cidade. Tal estágio é direcionado a estudantes de psicologia a partir do $3^{\circ}$ ano de graduação, das diferentes instituições de ensino de Maringá.

Depois de passar pelo processo de adaptação e compreensão a respeito do funcionamento do hospital, do serviço de psicologia, assim como, acompanhar atendimentos para fins de aprendizado e participar de supervisões semanais, o projeto oferece atendimento psicológico aos pacientes de todos os setores do hospital: Pronto Atendimento, Clínica Médica, Clínica Cirúrgica, Pediatria, Ginecologia e Obstetrícia.

No hospital, também existem os três setores de Unidade de Terapia Intensiva (UTI): Adulta, Pediátrica e Neonatal. Nas duas últimas, os atendimentos são feitos exclusivamente por profissionais do setor de Psicologia e seus respectivos residentes. Eventualmente, após certo tempo de projeto e de desempenho na atuação, os estagiários podem atender na UTI adulto, geralmente em congruência com algum profissional do setor.

De modo geral, tal atendimento é ofertado através de busca ativa nas enfermarias, onde buscamos por pacientes que aceitem atendimento, ou então por demanda da equipe, quando a equipe de enfermagem procura o setor de psicologia com pacientes e demandas específicas. Nesse caso, há possibilidade de maiores trocas entre os setores, pois o serviço de psicologia escuta a equipe e devolve um feedback a ela após o atendimento, o que faz com que ambos os setores discutam o caso e, na medida do possível, alinhem suas intervenções.

\subsection{A respeito do acolhimento e da ambiência}

O acolhimento como diretriz não se configura apenas na maneira como as pessoas são recebidas no hospital ou nas atitudes que nós, enquanto parte da equipe, julgamos ser ou não acolhedoras, vai além. Acolher implica diretamente em propiciar encontros e relações, é sobre "uma atenção especial ao tempo oportuno dos encontros, aos ritmos e fluxos de afetos, às necessidades em jogo, ao contexto, às técnicas de conversa (TEIXEIRA, 2003), aos modos de vida que se encontram e se confrontam" (BRASIL, 2011b, p. 57).

Desse modo, ocupando o lugar de estagiárias, o serviço de psicologia ofertado pelo HUM nos lança diretamente a tais encontros e relações. Após a inserção e período de adaptação, o primeiro e grande aprendizado, que estará presente em todos os atendimentos ofertados dali adiante, é que antes de tudo, devemos escutar o paciente. Ao chegarmos até ele, nos apresentarmos, e disponibilizarmos nossa presença e serviço, a primeira coisa que escutamos é 
se ele aceita ou não. Isso é extremamente importante para a manutenção da - pouca - autonomia que resta ao paciente, e da possível construção de vínculo, pois o serviço de psicologia é o único que o paciente tem licença para recusar.

Após esse primeiro momento, encaixam-se "às necessidades em jogo" (BRASIL, 2011 b, p. 57), porque oferecemos uma escuta ativa e qualificada, o paciente pode ser ouvido a respeito do que lhe é mais emergente, tanto em termos emocionais quanto em termos de vivência, indo além do sintoma físico que lhe causou a hospitalização e que - provavelmente já foi diagnosticado e biologicamente "destrinchado" para ele pela equipe.

A escuta ativa, por sua vez, vai além de uma "triagem" sobre a vida do paciente, mas, como destaca Oliveira et al (2018):

[...] envolve interesse pelo que está sendo dito, a aproximação corporal e o uso de expressões verbais de encorajamento à continuidade da fala no intuito de identificar a real demanda do paciente. Essa prática requer concentração e energia por parte do profissional. [...] Essa escuta vincula o assistido ao sistema e aos profissionais tornando o tratamento mais resolutivo. A resolução e confiança são oferecidas ao paciente pela escuta de suas queixas e temores, direcionando-o a uma autorreflexão do processo de saúde-doença (OLIVEIRA et al, 2018, p. 34)

Tal abordagem, assim como o trabalho de ouvir quem aquele paciente é e o que ele tem a dizer, ameniza a estranheza da hospitalização e da estigmatização por diagnósticos - abordada anteriormente -, e coloca o paciente enquanto sujeito em cena, possibilitando a aproximação entre ele e a equipe, gerando vínculo entre eles.

Desse modo, também lançamos mão de outras estratégias que se configuram como acolhedoras, como atender o paciente em outro lugar que não o leito. Além da reafirmação do sigilo - uma vez que os quartos no HU são coletivos -, retirar o paciente do ambiente estéril, asséptico e padronizado do leito e da enfermaria e levá-lo para um ambiente mais familiar, como o solário e a brinquedoteca - no caso das crianças - novamente, ameniza a angústia envolvida no processo de hospitalização, pois aproxima, na medida do possível, o paciente a aspectos do seu cotidiano humano.

A ambiência hospitalar, segundo o Ministério da saúde (BRASIL, 2004) diz sobre o

Tratamento dado ao espaço físico entendido como espaço social, profissional e de relações interpessoais que deve proporcionar atenção acolhedora, humana e resolutiva, considerando alguns elementos que atuam como catalisadores da inter-relação homem x espaço (BRASIL, 2004, p. 5) 
Para tanto, o Ministério da saúde (BRASIL, 2004) considera que a noção de ambiência deve ser baseada em eixos que concebem o espaço como capaz de ser suscitador de reflexões, de que deve ser confortável e privativo, exaltando elementos naturais que afetam o homem como luz e cor - assim como, ser funcional para a equipe de trabalho. Ou seja, a ambiência vai além da configuração arquitetônica do espaço, mas também versa sobre a forma como esse espaço é disposto, organizado e decorado, tendo em vista que ele afeta diretamente os sujeitos que o habitam e as suas relações. Dessa forma, percebe-se que a ambiência se torna um meio pelo qual se pode ofertar com maior resolutividade um atendimento acolhedor e, consequentemente, mais humanizado.

A esse respeito, algumas atividades realizadas pela equipe hospitalar, em que nós enquanto estagiários de psicologia somos convidados a contribuir, colaboram para tal ambiência no hospital. Desde ajudar na organização e disposição das cadeiras para os concertos musicais da semana da criança até decorar o hospital para o natal. Nesta última, ao final do ano, ajudamos membros da equipe de saúde a montar diversas árvores de natal e outros enfeites e espalhá-los pelo o hospital. Tal atividade, baseada na diretriz de ambiência, reverbera de vários modos nos sujeitos que compõem o espaço, mas destacamos que nós do setor da psicologia desfrutamos de um gatilho para iniciar um atendimento com uma conversa amena, visando a criação de vínculo, mas que em outros casos, acaba aparecendo como suscitador de reflexões e de conteúdo para o atendimento. O fato é que não se trata apenas de decorar o hospital para o natal, mas de proporcionar humanização para o processo de hospitalização que ocorre nesse período do ano.

Ainda sobre a ambiência, outro espaço importante é a brinquedoteca. O brincar é característico da infância, sendo um comportamento que possui papel importante em um desenvolvimento saudável (GUARIZI et al, 2018). Se o ambiente hospitalar já é atípico e despersonalizante para adultos, para as crianças pode se tornar ainda mais angustiante. Ter um espaço onde a criança pode ter acesso ao lúdico, a brinquedos e livros, e também à socialização - na medida do possível - com outras crianças, propicia um cuidado humanizado. Dessa forma, quando possível, ofertamos aos pacientes da pediatria a possibilidade de atendê-los na brinquedoteca do hospital, de modo que possam se sentir mais confortáveis e possam se comunicar segundo a sua própria linguagem. Além disso, existem outros aspectos relacionados à humanização do cuidado de crianças no ambiente hospitalar, que serão descritas a seguir.

\subsection{Humanização no cuidado com crianças hospitalizadas}


Como já abordado anteriormente, a hospitalização representa uma quebra na rotina das pessoas, além de comumente acarretar a despersonalização dos sujeitos e consolidar o estigma de doente. Por estarem em pleno desenvolvimento, nas crianças, essas alterações podem ser ainda mais traumáticas. Sadala e Antônio (1995) chegam a tratar da hospitalização na infância como uma crise que repercute no desenvolvimento psicossocial e intelectual da criança. $\mathrm{O}$ paciente pediátrico é inserido em um ambiente que, na maioria das vezes, não é planejado para atender à subjetividade e às necessidades de cada criança (RIBEIRO et al, 2017).

De acordo com Bortolote e Brêtas (2008), o espaço físico, os objetos e as pessoas com as quais a criança tem contato vão influenciar diretamente na maneira como ela lida com a hospitalização. Nesse sentido, as práticas de humanização buscam interferir nesses aspectos, tornando esse processo menos danoso. No Hospital Universitário de Maringá, o setor de psicologia participa e desenvolve diversas ações que visam à humanização do cuidado com as crianças hospitalizadas, como a confecção de cartazes no aniversário dos pacientes pediátricos, o desenvolvimento de atividades conjuntas temáticas em datas comemorativas, atendimentos lúdicos na brinquedoteca e outros - atividades que serão detalhadas em seguida.

Caso algum dos pacientes pediátricos faça aniversário durante sua internação, o setor de psicologia se organiza para colocar cartazes e bexigas para enfeitar seu leito. É importante averiguar com o setor de enfermagem se o leito do aniversariante pode ser enfeitado, já que se deve considerar a possibilidade de contaminação e considerar se não há nenhum problema com os outros pacientes que dividem o quarto com aquela criança. Assim, nós, enquanto estagiários de psicologia, conversamos com a própria criança, caso haja possibilidade, e com seu acompanhante, procurando envolvê-los na decoração e confecção dos cartazes. Então, decoramos o leito e cantamos parabéns. Vale ressaltar que buscamos sempre fazer os cartazes com personagens que as crianças gostem, com cores e temáticas escolhidas por elas.

Assim, essa forma de comemorar o aniversário no ambiente hospitalar é baseada principalmente nas diretrizes de ambiência, de acolhimento e de clínica ampliada da PNH, já que envolve, de forma simples, a produção de um espaço físico mais acolhedor, promovendo o envolvimento e a implicação do paciente e de seu acompanhante nesse processo, apostando na importância da relação afetiva do sujeito com o espaço em que está inserido, cultivando vínculos, promovendo a valorização da vida e o protagonismo do paciente em seu processo de adoecimento dentro do hospital e evidenciando uma concepção de saúde mais ampla (BRASIL, 2011b; COSTA et al, 2015).

Com relação ao desenvolvimento de atividades lúdicas e temáticas em datas comemorativas, no carnaval de 2020, foi organizada uma folia para que as crianças pudessem 
comemorar essa data. Essa atividade foi idealizada por um conjunto de profissionais de vários setores, dentre eles, a psicologia. Foram distribuídos adereços carnavalescos para todas as crianças internadas tanto na Pediatria quanto no Pronto Atendimento e aquelas que podiam sair do leito foram convidadas a participar da folia. Durante a atividade, as crianças puderam se fantasiar, tocar instrumentos e brincar umas com as outras.

Outra atividade organizada foi a "Semana da Criança", em que durante a semana do dia 12 de outubro de 2019, foram ofertadas às crianças hospitalizadas atividades lúdicas diárias, desde concertos musicais, contação de histórias, leitura de livros até oficina de confecção de brinquedos. Nesta última, as crianças que tinham a possibilidade de sair do leito foram encaminhadas até o solário onde tiveram acesso a materiais de papelaria, artesanato e recicláveis, assim como orientação para o passo a passo, para que confeccionassem determinados tipos de brinquedos propostos. Nessa atividade, os acompanhantes das crianças, além de auxiliá-las, também puderam participar da oficina.

Tais propostas de atividade também se constituem enquanto forma de acolhimento e clínica ampliada, pois tratam de uma forma de pensar nas demandas e necessidades das crianças - dadas naquela circunstância de suas vidas -, buscando, minimamente, satisfazê-las. Dessa forma, foi uma ação que visou à saúde das crianças, de forma a extrapolar os limites da concepção clássica de saúde restrita apenas ao biológico do corpo. Além disso, a atividade lúdica traz novos sentidos para a internação da criança, torna-se possível ressignificar o período que elas passam hospitalizadas, de tal forma que nem tudo que se remete ao hospital precisa ser relacionado a sofrimento (BRASIL, 2011b).

\subsection{A clínica ampliada e o trabalho multidisciplinar}

Um conhecimento enraizado em nosso processo de formação e de período de atuação como estagiárias no HUM, é de que nenhuma pessoa se limita às aparências e repetições dos sintomas das doenças com as quais convive. Este é o cerne da clínica ampliada. Como elucida o Ministério da Saúde (BRASIL, 2007a), a clínica precisa ser ampliada no sentido de oferta de serviço. Não basta, apenas, ofertar um cuidado restrito às manifestações biológicas da doença. É preciso olhar para o todo, e consequentemente, para a singularidade de cada pessoa doente.

Deste modo, a PNH define que clínica ampliada é um cuidado em saúde que se compromete e se responsabiliza com o sujeito, levando em consideração suas individualidades, 
intersetorializando as disciplinas, reconhecendo as limitações de cada área de atuação, e que, acima de tudo, exerce sua prática pautada em princípios éticos profundos (BRASIL, 2007a).

No estágio em Psicologia Hospitalar no HUM, observamos a clínica ampliada em nosso dia a dia. Como já apresentado anteriormente, os atendimentos que não ocorrem por busca ativa, ocorrem por solicitação da equipe de enfermagem, que reconhece a sua limitação diante de determinadas demandas e convoca a psicologia para contribuir nesse cuidado com o paciente em questão. Aqui, entende-se limitação no sentido de que uma especialidade não dá conta de tudo e precisamos uns dos outros. Também reconhecemos as limitações da nossa própria atuação, e sempre que necessário, trabalhamos para construir pontes entre o paciente e os outros profissionais da equipe, como com a assistência social em casos de vulnerabilidade, a fonoaudiologia em casos de puérperas que relatam dificuldade na amamentação, assim como, quando necessário, acompanhamos a visita médica para facilitar a comunicação e compreensão entre as partes, desde o diagnóstico até o tratamento e prognóstico.

\subsection{Visitas assistidas}

Outra atividade em que o setor de Psicologia contribui e que pode ser desempenhada por estagiários, é a visita assistida. No HUM, não são permitidas visitas de pessoas menores que 16 anos, mas em alguns casos, isso surge como demanda. A equipe de enfermagem a identifica, e quando avalia que o quadro do paciente possibilita tal encontro, comunica o setor de Psicologia. Este, por sua vez, vai atender o paciente e procurar ouvir o que ele tem a dizer sobre isso, sobre a relação que possui com essa criança/adolescente e a forma como a separação causada pela hospitalização os tem afetado.

Aqui, consideramos que quando alguém é hospitalizado, deixa-se "de ter os ecos que no seu cotidiano lhe confirmavam sua própria existência. Assim, tudo o que vier dos territórios afetivos e permitir essa afirmação íntima pode contribuir para o seu tratamento. " (BRASIL, 2007b, p. 9). Portanto, depois do que já foi feito, conversamos com a equipe de enfermagem sobre a viabilidade dessa visita, se é uma internação prolongada, se a expectativa de alta é demorada, se o paciente não tem nenhuma intercorrência que possa colocar em risco a saúde do visitante, como presença de bactéria multirresistente, por exemplo, entre outros aspectos que envolvem a situação - sempre tendo em vista que cada caso é um caso e deixando o paciente a par de tudo. 
Após tal alinhamento com a equipe, marca-se a visita em um dia e horário que seja possível tanto para o visitante quanto para o estagiário. Quando tal momento chega, antes de acompanhar o visitante até o paciente, o representante da psicologia faz um atendimento com esse visitante, criança/adolescente, na sala do setor de psicologia que se destina a esse fim, visando prepará-lo para adentrar no ambiente hospitalar, assim como, conversar sobre as fantasias que possui sobre seu ente internado em contraponto com a realidade dele.

Em seguida, quando possível, o paciente é trazido à sala mencionada acima para que a criança/adolescente não seja exposta aos outros setores do hospital - quando não é possível, alinha-se com a enfermagem a melhor opção. Assim, o estagiário se retira durante determinado tempo para que o visitante e o paciente possam ter um pouco de privacidade e conforto. Após o término do tempo combinado para a visita, o estagiário avisa que está na hora da despedida. O paciente retorna ao seu leito, e o estagiário termina o atendimento com a criança/adolescente, acolhendo os sentimentos e reações reverberados pelo encontro.

Vale destacar que a visita assistida é uma ação abarcada pelo leque de possibilidades que a diretriz "Visita aberta", da PNH, nos proporciona, além disso, tendo em vista a noção de clínica ampliada, que deve nortear o cuidado em saúde, o direito à visita é crucial para a realização assertiva desse cuidado. Esse direito, que visa ampliar o acesso das pessoas aos pacientes internados, promove a garantia da relação entre o paciente e o seu contexto social, indo de encontro com a despersonalização e favorecendo a manutenção do projeto de vida do paciente. (BRASIL, 2007b). Desse modo, novamente ratificamos que a visita reafirma a clínica ampliada, uma vez que toda a equipe se compromete e se responsabiliza eticamente pelo cuidado em saúde, "equilibrando o combate à doença com a produção de vida" (BRASIL, 2007a, p. 15).

\subsection{Unidade de Terapia Intensiva (UTI)}

Pacientes cujos quadros de saúde são mais graves são internados na UTI e no HUM, como já mencionado, há três setores de UTI, mas os estagiários de psicologia atuam apenas na UTI adulta, dessa forma, nesse artigo iremos abordar apenas o trabalho realizado no setor destinado aos adultos. Cada paciente internado na UTI tem uma ficha que, após preenchida pelo setor de psicologia, é colocada no leito do paciente, para que todos os profissionais de saúde do hospital tenham acesso a ela. Essa ficha contém alguns dados gerais do paciente, como 
utilização de medicamentos, uso de álcool ou drogas, alguns aspectos relativos à sua rotina, nome dos familiares, contato para emergências e aspectos socioculturais relevantes.

O preenchimento da ficha é realizado com ajuda de um familiar durante uma conversa. É comum que os familiares esqueçam de algumas informações quando conversam com os médicos anteriormente, por ser uma conversa mais objetiva, portanto essa conversa com algum representante do setor de psicologia costuma ser mais longa, trata-se de um momento em que os familiares podem assimilar o internamento e lembrar de informações importantes que possam auxiliar a equipe no cuidado com o paciente. Nesse momento, o familiar é convidado a pensar sobre o que o paciente internado representa para ele, refletindo sobre o quanto aquela pessoa é importante para ele, e também é convidado a elaborar uma frase que resuma isso. Essa frase é impressa e colocada no leito do paciente com o nome do familiar que a disse.

Tomando novamente como base o Caderno HumanizaSUS do Ministério da Saúde (BRASIL, 2011b), esse primeiro contato da família com o setor de psicologia caracteriza uma das etapas do acolhimento, pois diz respeito à forma como recebemos as pessoas nesse setor do hospital, levando em consideração as suas demandas e necessidades subjetivas. Outro aspecto importante desse acolhimento inicial é a frase que fica no leito do paciente, já que se trata de uma forma de personalizar aquele espaço que está sendo ocupado por ele. Essa ação contribui com a diretriz da ambiência e proporciona uma atenção mais acolhedora, já que a frase também é constante referência à humanidade do paciente e à importância dele para sua família, o que pode exercer função de estímulo para os profissionais de saúde responsáveis pelo cuidado com as pessoas internadas na UTI.

Uma vez hospitalizados no setor em questão, os pacientes podem receber visitas em horários pré-estabelecidos, sendo que o hospital permite que até duas pessoas entrem para ver o paciente por horário de visita, uma de cada vez. As visitas que acontecem durante o horário de funcionamento do setor de psicologia são acompanhadas por psicólogos ou estagiários e, quando possível, o estagiário ou psicólogo explica ao familiar como o paciente está, buscando prepará-lo para o que irá encontrar. As regras para visitantes são mais restritas na UTI, uma vez que o quadro dos pacientes é mais delicado e exige maior cuidado.

A despeito dessas restrições, é possível que a rede de apoio do paciente esteja presente durante seu tratamento, seja parte e esteja implicada nesse processo. Esse aspecto é essencial quando se tem a PNH como parâmetro para uma atenção mais humanizada, uma vez que leva em consideração a concepção de clínica ampliada, que compreende o processo de adoecimento e sofrimento como processo amplo e entende que o restabelecimento da saúde do paciente depende de sua rede de suporte (BRASIL, 2011b). 
Além disso, em um dos horários disponíveis para visita, o médico responsável atualiza a situação do paciente para o familiar presente, essa explicação pode ou não ser acompanhada pela psicologia - ela costuma ser acompanhada quando o setor de psicologia ou a própria equipe médica percebe que se trata de uma família com dificuldades de compreensão a respeito do quadro do paciente. Assim, a função do profissional ou estagiário que participa dessa conversa é auxiliar a comunicação entre a equipe médica e a família do paciente. Essa é mais uma maneira de implicar a rede de suporte do paciente nesse processo de cuidado, ou seja, de concretizar a clínica ampliada e também de acolher a família da pessoa internada.

Outro trabalho importante realizado pelo setor de psicologia na UTI adulta é a participação na visita multiprofissional, momento em que os profissionais de saúde do hospital se reúnem para discutir o caso de cada paciente. O trabalho da psicologia é, principalmente, atualizar os profissionais a respeito da família de cada paciente, das visitas que ele vem recebendo e da compreensão familiar a respeito de seu quadro médico. Trata-se de um momento em que a diretriz da clínica ampliada está em evidência, porque os profissionais estão levando em consideração a "multiplicidade de maneiras de se pensar e de se agir sobre os processos de adoecimento e de cuidado.” (BRASIL, 2011b, p. 56).

\subsection{Outras possibilidades no HUM}

O setor de psicologia ainda realiza acompanhamento de óbito em qualquer setor do hospital. Quando pacientes que estão sendo atendidos pelo setor de psicologia falecem, o setor de enfermagem contacta nosso serviço para que os psicólogos ou estagiários possam acompanhar a família do paciente durante a realização dos trâmites legais que acontecem no hospital e, caso a família queira, para prepará-la e acompanhá-la na despedida do ente querido no necrotério. A função do setor, nesse momento, é de acolhimento, proporcionando suporte para a família e concluindo o atendimento prestado durante a hospitalização do paciente. Também existe o acompanhamento em caso de óbito para familiares de pacientes que, por alguma razão, não estavam sendo acompanhados por psicólogos. Nestes casos o profíssional se inteira do caso ao ler rapidamente o prontuário do paciente e conversar com a equipe de saúde que o atendia, prestando o mesmo auxílio mencionado acima (BRASIL, 2011b).

Além de tudo que foi relatado acima, o setor de psicologia tem o importante trabalho de mediar a relação da equipe do hospital com os pacientes e suas famílias (AZEVEDO; CREPALDI, 2016). Essa função contribui diretamente com a humanização do cuidado, uma 
vez que proporciona a possibilidade de o paciente e de suas famílias terem um papel mais ativo no processo de cura, aspecto fundamental na diretriz da clínica ampliada, e proporciona mais autonomia ao paciente, constituindo uma ação acolhedora (BRASIL, 2011b). No HUM, os estagiários de psicologia e os psicólogos também podem acompanhar visitas médicas, buscando auxiliar o paciente na compreensão de seu quadro clínico, conversar sobre o direito a acompanhante do paciente com o setor de enfermagem, buscando sanar dúvidas dos pacientes a esse respeito e assegurar o direito deles, e, dentre outras funções, pedir auxílio da assistência social para obter orientações e benefícios ao paciente e à sua família.

\section{Considerações finais}

É importante salientar que, a partir das pesquisas realizadas para elaboração desse artigo e também a partir das reflexões a respeito do estágio realizado dentro do projeto de extensão no HUM, ficou claro o quanto toda prática do psicólogo hospitalar é pautada na premissa da humanização do cuidado, além das ações e funções específicas que explicamos acima, todo o processo de escuta realizado com os pacientes e com suas famílias configura humanização, assim como o trabalho na preparação de pacientes para determinados procedimentos, a preparação do luto, a amenização de angústias decorrentes da situação de hospitalização e muitas outras práticas.

Outro aspecto importante é que, diante da retomada histórica referente ao surgimento do SUS e a elaboração e publicação da PNH e diante da atuação do psicólogo hospitalar no HUM, conseguimos frisar a importância da humanização do cuidado com pacientes hospitalizados, explicando quais os fundamentos desse processo e apresentando alguns de seus resultados positivos. A partir das discussões acima, também fica mais tangível conceber ações concretas que partam da equipe de saúde e que estejam em consonância com as diretrizes da PNH. No texto, trouxemos também algumas possibilidades, dentre as mais diversas possíveis, de articulação entre a Psicologia e a aplicação da PNH no contexto de um hospital escola, buscando ratificar a relevância e a potência do serviço de Psicologia na implementação e manutenção dos processos de humanização.

Salientamos também que, apesar da importância da psicologia e da potência tanto de seu escopo teórico quanto prático nesses processos, durante as pesquisas para embasamento teórico das práticas realizadas no HUM, foi possível notar a escassez de trabalhos na área da Psicologia que explorassem a execução da PNH nos serviços de saúde de alta complexidade, tal qual no hospital em questão. Diante desse panorama, esperamos que esse artigo possa abrir 
novas perspectivas de trabalho sobre o tema, pois acreditamos que existem caminhos ricos e promissores a serem explorados no que tange a relação entre a psicologia e a PNH.

Por fim, destacamos que o atual contexto de pandemia de COVID-19, inviabilizou temporariamente várias das atividades de humanização no hospital, haja vista que o cenário pede medidas de restrição de contato e de fluxo de pessoas no hospital. Consideramos importante a produção de conteúdo científico que abarque a temática "humanização no hospital em tempos de COVID-19", mas que por conta da delimitação metodológica do presente estudo, não o abordamos, deixando aberta a possibilidade para uma próxima produção das autoras.

\section{REFERÊNCIAS}

AZEVEDO, A. V. dos S.; CREPALDI, M. A. A Psicologia no hospital geral: aspectos históricos, conceituais e práticos. Estud. Psicol. (Campinas), v. 33, n. 4, p. 573-585, 2016.

ANGERAMI-CAMON, V. O Psicólogo no Hospital. In: ANGERAMI-CAMON, V. (Org.). Psicologia Hospitalar: teoria e Prática. São Paulo: Thomson, 2003. p. 1-14.

BRASIL. Conselho Nacional de Secretários de Saúde. Sistema Único de Saúde/Conselho Nacional de Secretários de Saúde. Coleção Para Entender a Gestão do SUS. Brasília, DF, 2011a.

BRASIL. Ministério da Saúde. Secretaria de Atenção à Saúde. Departamento de Ações Programáticas e Estratégicas. Atenção hospitalar/Ministério da Saúde, Secretaria de Atenção à Saúde, Departamento de Ações Programáticas e Estratégicas. Série B. Textos Básicos de Saúde: Cadernos HumanizaSUS. Brasília, DF, 2011 b.

BRASIL. Ministério da Saúde. Secretaria de Atenção à Saúde. Núcleo Técnico da Política Nacional de Humanização. HumanizaSUS: Clínica ampliada, equipe de referência e projeto terapêutico singular. Brasília: Ministério da Saúde, 2007a.

BRASIL. Ministério da Saúde. Secretaria de Atenção à Saúde. Núcleo Técnico da Política Nacional de Humanização. HumanizaSUS: Visita aberta e direito a acompanhante. Brasília: Ministério da Saúde, 2007b.

BRASIL. Ministério da Saúde. Secretaria-Executiva. Núcleo Técnico da Política Nacional de Humanização. HumanizaSUS: ambiência. Brasília: Ministério da Saúde, 2004.

BORTOLOTE, G. S.; BRÊTAS, J. R. da S. O ambiente estimulador ao desenvolvimento da criança hospitalizada. Revista da Escola de Enfermagem da USP, v. 42, n. 3, p. 422-429, 2008.

CONSELHO FEDERAL DE PSICOLOGIA. Institui a Consolidação das Resoluções relativas ao Título Profissional de Especialista em Psicologia e dispõe sobre normas e procedimentos para seu registro. Resolução $\mathbf{n}^{\mathbf{0}} \mathbf{0 1 3 / 2 0 0 7}$, de 14 de setembro de 2007. Disponível em: < https://site.cfp.org.br/wp-content/uploads/2008/08/Resolucao_CFP_nx_013-2007.pdf>.

Acesso em: 04 jun. 2020.

COSTA, A. P. et al. A experiência da Ambiência como uma diretriz da Política Nacional de Humanização da Atenção e Gestão do SUS. Projetar, p. 1-15, 2015.

OLIVEIRA, M. J. S. et al. A escuta ativa como estratégia de humanização da assistência em saúde. Revista Saúde e Desenvolvimento Humano. v. 6, n. 2, p. 33-38, 2018. 
PASCHE, D. F.; PASSOS, E. A importância da humanização a partir do Sistema Único de Saúde. Rev. Saúde Públ. Santa Cat., v.1, n. 1, 2008.

PEREIRA, R. P. Política Nacional de Humanização (PNH) aplicada aos serviços hospitalares: revisão de literatura e análise das estratégias utilizadas para efetivação da humanização nos hospitais vinculados ao Sistema Único de Saúde (SUS) com ênfase na atuação de Grupos de Trabalho em Humanização (GTHs). 2019. Dissertação. Brasil.

NEDER, M. (2005). Mathilde Neder - Homenageado. Psicologia: Ciência e Profissão, v. 25, n. 2, p. 332-332, 2009.

RIBEIRO, J. P. et al. Ambiência da pediatria: produção de subjetividades nas crianças internadas. Saúde (Santa Maria), v. 43, n. 1, p. 123-131, 2017.

RUDNICKI, T; SCHMIDT, B. Psicologia da Saúde e Psicologia Hospitalar: Aspectos Conceituais e Práticos. In: ELIAS, V. et al. Horizontes da psicologia hospitalar: saberes e fazeres. São Paulo: Atheneu, 2015, p. 3-10.

SADALA, M. L. A.; ANTÔNIO, A. L. de O. Interagindo com a criança hospitalizada: utilização de técnicas e medidas terapêuticas. Revista Latino-Americana de Enfermagem, v. 3, n. 2, p. 93-106, 1995.

\footnotetext{
i Doutora em Psicologia pela Universidade de São Paulo (USP) e professora do curso de Psicologia da Universidade Estadual de Maringá (UEM). Email: karol.lukachaki@ gmail.com

ii Acadêmica do curso de Psicologia da Universidade Estadual de Maringá (UEM). Email: barbaracarolina214@gmail.com

iii Acadêmica do curso de Psicologia da Universidade Estadual de Maringá (UEM). Email: mariliadhg@gmail.com
} 